\title{
Pandemic Coronavirus Disease-19-Induced Obsessive Compulsive Disorder on the Bank Employee
}

\author{
Sutan Dassep Purnama ${ }^{D}$, Mustafa M. Amin*(D), Elmeida Effendy (D) \\ Department of Psychiatry, Faculty of Medicine, University of North Sumatra, Medan, Indonesia
}

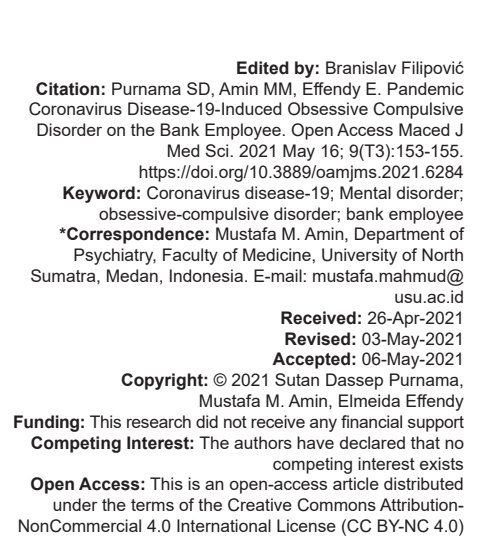

\begin{abstract}
BACKGROUND: Coronavirus disease-19 (COVID-19) is a highly contagious viral disease that affects respiratory system and other organs. It is transmitted through air or contact of contaminated surfaces. Thus, physical and social distancing, hand washing with soap, or hand sanitizer are greatly persuaded. Interestingly, this pandemic does not only affect physical health, but also mental disorder, including obsessive-compulsive disorder (OCD) that is marked with the presence of either obsession or persistent compulsive behavior, or in the most common form, both are present. Obsession is thought, image or desire that preoccupies someone's mind which commonly is related to anxiety. Compulsion, in the other hand, is repetitive behavior that strongly derives individual to do so to achieve fulfillment of one's obsession that is not considered normal on the bases of daily norm.

CASE REPORT: A 26-year-old woman as a bank employee admitted of doing repetitively unreasonable hand washing and shower within approximately the past 3 months. She even washes her hands more than 10 times in an hour and takes shower more than 5 times a day. She admitted that this is her very first experience and all were started at the beginning of COVID-19 pandemic.

CONCLUSION: COVID-19 pandemic also causes serious mental disorders and has become such a nightmare or worst scenario for those experiencing OCD. Physical and social distancing, hand washing with soap, or hand sanitizer are greatly.
\end{abstract}

\section{Introduction}

Coronavirus disease-19 (COVID-19) affects respiratory system and may lead to severe acute respiratory distress. The most common symptoms vary, from fever, cough, to dyspnea [1], [2]. Furthermore, other symptoms including confusion, chest pain, throat sore, congested nose, anosmia, headache, weakness, vomiting, and diarrhea are also reported. This disease also poses a serious threat as the number of deaths increases worldwide [1], [2]. Researchers are currently still looking for potential treatment regiments such as vaccines, monoclonal antibodies, small molecular drugs, protease inhibitor, peptides, or interferon-based therapy to overcome this pandemic [2]. COVID-19 is transmitted from man to man through droplets, coughs, or sneezes. It may also spread through the air or through touching on contaminated surfaces. Therefore, physical and social distancing, hand washing with soap, or hand sanitizer are greatly recommended [3]. It is also not uncommon for the media to announce COVID-19 as personal nightmare or worst case scenario particularly for those living with obsessive-compulsive disorder (OCD) [4].

COVID-19 pandemic also poses serious threats to mental health [5]. This situation also contributes to more individuals reporting to experience anxiety related to danger and potential contamination of the disease, attempt on self-isolation, as well as excessive fear of foreigners that along with social-economic effects, has become known as COVID stress syndrome which, in turn, leads to anxiety disorder, such as OCD [6].

OCD is marked with the presence of either obsession or persistent compulsive behavior, or in the most common form, both are present. Obsession is thought, image or desire that preoccupies someone's mind which commonly is related to anxiety. To overcome this, individuals with pre-occupied obsession have to fulfill what the obsession desires that lead to compulsion even when the individuals actually do not agree on doing that. Compulsion, in the other hand, is repetitive behavior that strongly derives individual to do so to achieve fulfillment of one's obsession that is not considered normal on the bases of daily norms [7].

\section{Case Report}

A 26-year-old woman, FL, a Moslem Javanese, was taken to the outpatient psychiatry clinic of North Sumatera University Hospital by her sister, Mrs. HN, a 32-year-old Moslem Javanese with the main complaint 
due to unreasonable repetitive hand washing and showering within the past 3 months. FL admitted that she washes hands more than 10 times in an hour and takes shower 5 times a day. She stated that she feels filthy all the time and whenever she tries to stop, she will be anxious instead of knowing that it is not true. This behavior troubles her at work that she even received reminder from her boss 2 months earlier. FL pictured herself as a perfectionist, sometimes even makes her other coworkers become less than herself. This makes her become separated from her coworkers and receives less attention. She already has been working at one government bank office for 4 years and usually spends $10-12 \mathrm{~h}$ a day to work. She admitted that she frequently was running behind the deadline and blames that the deadline was way too short for her to complete the assignments. Over the past 3 months, FL always brought her toiletries and clothes to office, and felt unable to resist the temptation of washing hands and taking shower. This was even getting worse when FL found that one of her coworkers was admitted in the intensive care due to COVID-19 and some of her other coworkers were confirmed of having COVID-19 after a massive rapid test at her office in June 2020 or around 4 months earlier. Any previous medical issues were not found, neither delusions nor hallucination was present, and no history of substance abuse was noted.

From the above examination and in accordance with PPDGJ III, FL was diagnosed with OCD. She was prescribed with sertraline $100 \mathrm{mg}$ twice a day as well as several other non-pharmacological approaches, such as education for patient and her family, cognitive behavioral therapy (CBT), breathing retraining, and exposure and response prevention (ERP).

\section{Discussion}

Although this COVID-19 pandemic, number of individuals with mental health issues is increasing rapidly, as shown in this particular case report, our patient FL was newly diagnosed with OCD without any initial history before this pandemic. What actually important is to punctually follow the health protocols during pandemic which comprises 3 points; hand washing using soap, physical and social distancing, and wearing masks. The above situation may lead to OCD particularly to individuals with anankastic personality. Anankastic personality is characterized with intense and strong attention to details and arrangements, perfectionism, and strong urge to control others to do as what that individuals feel proper [7].

In this case, we provide pharmacological and non-pharmacological therapy. The pharmacological therapy of choice is the selective serotonin reuptake inhibitor class of drugs, namely, sertraline starting at a dose of $2 \mathrm{mg} \times 50 \mathrm{mg}$ which will continue to be given to patients for the initial 3 months, and after that, it is recommended that repeat control and treatment can be carried out for the next 12 months. As for the nonpharmacological CBT with ERP, CBT is a psychological treatment based on our thinking that our feelings are influenced by our thoughts (or "cognition") and beliefs, and by how we behave. For example, if we have negative thoughts, this can lead to negative behavior, which can affect how we feel. CBT helps people reassess the meaning of their thoughts and actions. ERP helps people deal with situations or things that make them OCD [7], [8].

Breathing retraining while temporary overbreathing and hyperventilation are not specifically dangerous, continued overbreathing can leave you feeling exhausted or "on edge" so that you're more likely to respond to stressful situations with intense anxiety and panic. Gaining control over your breathing involves both slowing your rate of breathing and changing your breathing style. Use the following steps to be well on your way to developing a better breathing habit. Ensure that you are sitting on a comfortable chair or laying on a bed: Take a breath in for $4 \mathrm{~s}$ (through the nose if possible), hold the breath for $2 \mathrm{~s}$, release the breath taking $6 \mathrm{~s}$ (through the nose if possible), then pause slightly before breathing in again [8].

\section{Conclusion}

The current COVID-19 pandemic outbreak is causing serious mental health problems. Important things to do during this pandemic include physical distancing, social distancing, washing hands with soap, and water or sufficient hand sanitizer.

\section{References}

1. Yuki K, Fujiogi M, Koutsogiannaki S. COVID-19 pathophysiology: A review. Clinical Immunology. 2020; 215:108427. https://doi. org/10.1016/j.clim.2020.108427

2. Lotfi M, Hamblin MR, Rezaei N. Since January 2020 Elsevier has created a COVID-19 resource centre with free information in English and Mandarin on the novel Coronavirus COVID-19. The COVID-19 resource centre is hosted on Elsevier Connect, the company's public news and information. Clin Chim Acta. 2020;508:254-66. https://doi.org/10.1016/j.cca.2020.05.044

3. Aardema F. COVID-19, obsessive-compulsive disorder and invisible life forms that threaten the self. J Obsessive Compuls Relat Disord. 2020;26:1-5. https://doi.org/10.1016/j.jocrd.2020.100558

4. Benatti B, Albert U, Maina G, Fiorillo A, Celebre L, Girone N, et al. What happened to patients with obsessive compulsive disorder during the COVID-19 pandemic? A multicentre report from tertiary clinics in Northern Italy. Front Psychiatry. 
2020;11:720. https://doi.org/10.3389/fpsyt.2020.00720 PMid:32793008

5. Moulding R, Hughes ME, Byrne L, Do M, Nedeljkovic M. Obsessive compulsive disorder. Dev Disord Brain Second Ed. 2016:173-90. https://doi.org/10.4324/9781315692289-11

6. Sheu JC, McKay D, Storch EA. COVID-19 and OCD: Potentia impact of exposure and response prevention therapy. J Anxiety Disord. 2020;76:102314. https://doi.org/10.1016/j. janxdis.2020.102314

\section{PMid:32980748}

7. World Health Organization. ICD-11-Mortality and Morbidity Statistics. Geneva: World Health Organization; 2018. Available from: https://www.icd.who.int/browse11//-m/en. [Last accessed: 15 May 2021].

8. NICE, Obsessive-Compulsive Disorder and Body Dysmorphic Disorder: Treatment. Nice, National Institute for Health and Care Excellence; 2005. p. 15-46. https://doi. org/10.4324/9781315561073-11 